\title{
Validation of the model of TSL isothermal decay in dosimetric $\alpha-\mathrm{Al}_{2} \mathrm{O}_{3}$ crystals
}

\author{
S.V. Nikiforov ${ }^{\mathrm{a}, *}$, A. Lushchik $^{\mathrm{b}}$, V. Nagirnyi ${ }^{\mathrm{b}}$, I. Romet ${ }^{\mathrm{b}}$, A.I. Ponomareva ${ }^{\mathrm{a}}$, D.V. Ananchenko ${ }^{\mathrm{a}}$, \\ E.V. Moiseykin ${ }^{\mathrm{a}}$

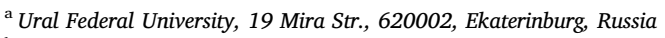 \\ ${ }^{\mathrm{b}}$ Institute of Physics, University of Tartu, W. Ostwald Str. 1, 50411, Tartu, Estonia
}

\section{A R T I C L E I N F O}

\section{Keywords:}

Aluminum oxide

Thermally stimulated luminescence

TSL build-up

Deep traps

Thermal ionization of $\mathrm{F}$ centres

\begin{abstract}
A B S T R A C T
New features of isothermal build-up of thermally stimulated luminescence (TSL) related to deep traps in aniondeficient alumina single crystals are revealed. It was found that the TSL build-up at $630-750 \mathrm{~K}$ depends on the structure of the glow curve and is associated with the presence of a high-temperature component with $\mathrm{T}_{\mathrm{m}}=700 \mathrm{~K}$. Isothermal TSL build-up for the peak at $573 \mathrm{~K}$ is well expressed in UV-irradiated samples and is very weak after sample irradiation by a pulsed electron beam. The TSL build-up for this peak is registered for the luminescence of $\mathrm{F}$ centres but is absent for the emission of $\mathrm{F}_{2}{ }^{2+}$ centres and chromium ions. The obtained results confirm the validity of the kinetic model of the TSL build-up that takes into account the process of thermal ionization of the excited states of $\mathrm{F}$ centres in aluminum oxide.
\end{abstract}

\section{Introduction}

Electronic structure, optical properties and the processes of radiation damage of aluminum oxide $\left(\alpha-\mathrm{Al}_{2} \mathrm{O}_{3}\right)$, that possesses technological, mineralogical and catalytic importance, have been the subject of thorough and long-term experimental and theoretical studies (see, for instance (Itoh and Stoneham, 2000; Valbis and Itoh, 1991; French et al., 1994; Kotomin et al., 1994; Evans, 1995; Kirm et al., 1999; Bos, 2001; Lushchik et al., 2008; Makhov et al., 2008; Popov et al., 2018), and references therein). Among numerous applications, a particular attention has been paid to the use of alumina as highly sensitive luminescent detectors of ionizing radiation (Akselrod et al., 1990; McKeever et al., 1999; Nikiforov et al., 2014; Surdo et al., 2016; Nikiforov and Kortov, 2017). So-called TLD-500 detectors are based on anion-deficient (sometimes named in literature as anion-defective) $\alpha-\mathrm{Al}_{2} \mathrm{O}_{3}$ with high concentration of as-grown oxygen vacancies, which is named in literature as $\mathrm{Al}_{2} \mathrm{O}_{3}: \mathrm{C}$.

The luminescence properties of dosimetric $\alpha-\mathrm{Al}_{2} \mathrm{O}_{3}$ crystals are largely affected by the presence and occupancy of deep traps (DT) (Milman et al., 1998; Yukihara et al., 2003; Nikiforov and Kortov, 2010; Surdo et al., 2014). Therefore, the study of the role of deep trapping centres in charge carrier transfer and thermally stimulated luminescence (TSL) is an important task. In practical terms, the investigation of TSL features for deep traps is rather relevant in view application prospects in dosimetry of high-dose (above $1 \mathrm{kGy}$ ) ionizing radiation (Nikiforov et al., 2014; Nikiforov and Kortov, 2014).

TSL associated with deep traps was found in anion-deficient crystals of aluminum oxide after irradiation with various types of radiation. Irradiation with a high-current pulsed electron beam $(130 \mathrm{keV})$ gives rise to TSL in the region of 500-600, 630-750 and $800-870 \mathrm{~K}$ (Nikiforov et al., 2014). An unusual effect of isothermal TSL build-up has been found for the peak at $700 \mathrm{~K}$ in the crystals irradiated with such beam (Nikiforov et al., 2017). The phenomenon of TSL build-up cannot be explained in the framework of the standard two-level model of TSL.

A model of the build-up that takes into account the process of thermal ionization of the excited states of $\mathrm{F}$ centres has been proposed (Nikiforov et al., 2017). A simplified energy band diagram of the model is presented in Fig. 1. It includes an F centre (two electrons trapped by an oxygen vacancy) and a deep electron trap, DET. It is known that the F-centre has one ground $\left({ }^{1} \mathrm{~S}\right)$ and two excited states $\left({ }^{1} \mathrm{P}\right.$ and ${ }^{3} \mathrm{P}$ ) (Evans, 1995). The singlet excited state ${ }^{1} \mathrm{P}$ is located near the bottom of the conduction band, so the probability of ${ }^{1} \mathrm{P}$ state ionization can be considered as temperature-independent. The $\mathrm{P}_{\mathrm{F}}$ transition is a process of thermal ionization of the triplet excited $\left({ }^{3} \mathrm{P}\right)$ state of the $\mathrm{F}$ centre, its probability is described by the Boltzmann factor (Nikiforov et al., 2017). The electrons released from the DET during thermal stimulation (transition $\mathrm{P}$ ) are captured by $\mathrm{F}^{+}$centres (one electron in an oxygen vacancy, transition $\gamma$ ) with the formation of $F$ centres in the excited

\footnotetext{
* Corresponding author.

E-mail address: s.v.nikiforov@urfu.ru (S.V. Nikiforov).
} 


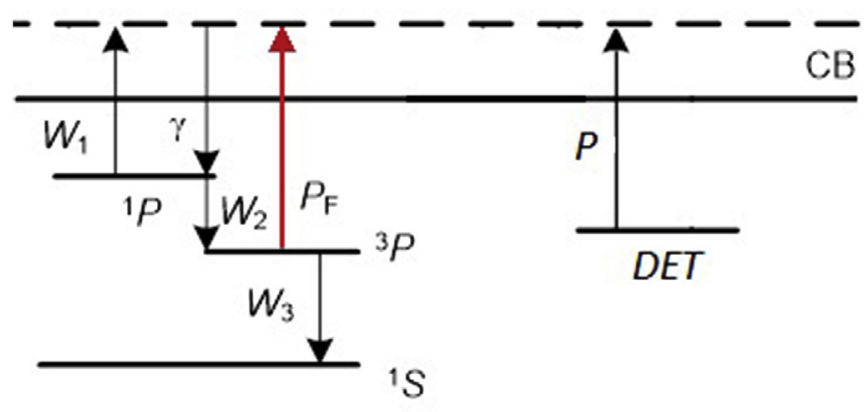

VB

Fig. 1. The energy band diagram of the TSL isothermal build-up model that involves thermal ionization of the excited states of $\mathrm{F}$ centres (see text for details).

state. Thermal ionization of the ${ }^{3} \mathrm{P}$ excited state of $\mathrm{F}$ centres leads to the significant electron inflow in the conduction band when the linear heating of an irradiated sample is terminated and an isothermal stage of TSL begins. Such excess of conduction electrons, which can be further trapped by recombination centres with the following luminescence, is a reason for TSL build-up in the model under discussion.

Calculations carried out in accordance with this model demonstrated good agreement of calculated intensity and duration of TSL build-up with the experimental values obtained at different temperatures and heating rates. In addition, the proposed model does not contradict to the absence of the build-up for the TSL at $800-870 \mathrm{~K}$, associated with deep hole traps.

It should be noted that the above-mentioned model ascribing the TSL build-up with the participation of F-centre excited states in alumina has not been supported by some authors (Pagonis et al., 2011; Chithambo et al., 2014). In particular, the data on thermally stimulated conductivity of $\alpha-\mathrm{Al}_{2} \mathrm{O}_{3}: \mathrm{C}$ have been reported to contradict the mechanism based on the $P_{F}$ transition leading to thermal ionization of the F-centre triplet excited state (Pagonis et al., 2011). Therefore, additional experimental study is needed to verify the proposed model. In particular, spectral and kinetic characteristics of isothermal TSL decay should be carefully studied for other TSL peaks (for example, at $570 \mathrm{~K}$ ) after different types of sample irradiation.

The aim of the present work is to study isothermal decay in the TSL peaks associated with deep traps and to obtain new data verifying the TSL model, which involves the thermal ionization of excited F centres.

\section{Samples and experimental methods}

The samples of commercial ionizing radiation detectors TLD-500 made of $\mathrm{Al}_{2} \mathrm{O}_{3}$ single crystals were studied. The detectors were in the shape of discs $1 \mathrm{~mm}$ thick and $5 \mathrm{~mm}$ in diameter. The samples were irradiated by UV light from a $150 \mathrm{~W}$ xenon lamp or an electron beam from a RADAN EXPERT accelerator at room temperature. The pulse duration of electron beam was $2 \mathrm{~ns}$, mean electron energy $(130 \pm 1)$ $\mathrm{keV}$, the current density $60 \mathrm{~A} / \mathrm{cm}^{2}$. The absorbed dose of $1.5 \mathrm{kGy}$ under irradiation by a single pulse was determined with a film dosimeter (Afanas'ev et al., 2005).

The technique of the measurements of isothermal TSL decay was as follows:

1) the samples were irradiated by a pulsed electron beam or UV light;

2) the samples were heated linearly with a selected rate $(2$ or $0.5 \mathrm{~K} / \mathrm{s})$ up to a specified temperature of an isothermal measurement $\left(\mathrm{T}_{\mathrm{is}}\right)$;

3) the specified temperature $T_{\text {is }}$ was kept for a certain time (up to $10 \mathrm{~min}$ ), during which the TSL decay curves were measured (an isothermal stage);

4) the samples were annealed in an oven at $1173 \mathrm{~K}$ during $15 \mathrm{~min}$ for emptying all charge carrier traps.

TSL was registered by a FEU-142 photomultiplier tube with the maximum of spectral sensitivity at $200-400 \mathrm{~nm}$. An optical filter CSC-7 (Krasniy Gigant Company, Russia) was used in front of the photomultiplier tube to remove heat radiation.

For the spectral studies of isothermal TSL decay, the samples were irradiated for $15 \mathrm{~min}$ at room temperature with a $400 \mathrm{~W}$ deuterium discharge lamp DDS-400 through an interference filter with a transmission band centered at $205 \mathrm{~nm}$. The TSL emission spectrum was measured using an ARC SpectraPro 300i grating monochromator equipped with a CCD detector with a spectral sensitivity in the range of $190-1100 \mathrm{~nm}$. The heating rate was $0.5 \mathrm{~K} / \mathrm{s}$. Each emission spectrum was measured within the temperature interval of $10 \mathrm{~K}$.

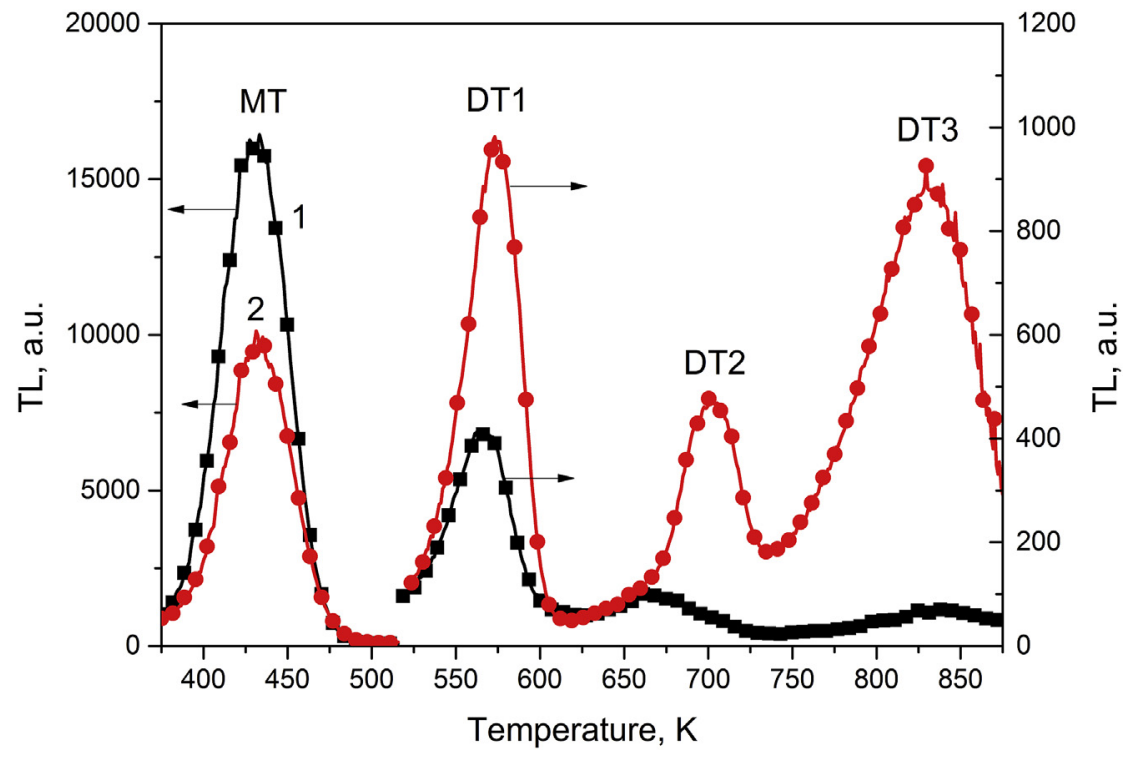

Fig. 2. TSL of two typical anion-deficient $\alpha-\mathrm{Al}_{2} \mathrm{O}_{3}$ single crystals irradiated by a pulsed electron beam ( $15 \mathrm{kGy}$ ). Heating rate was $2 \mathrm{~K} / \mathrm{s}$. 


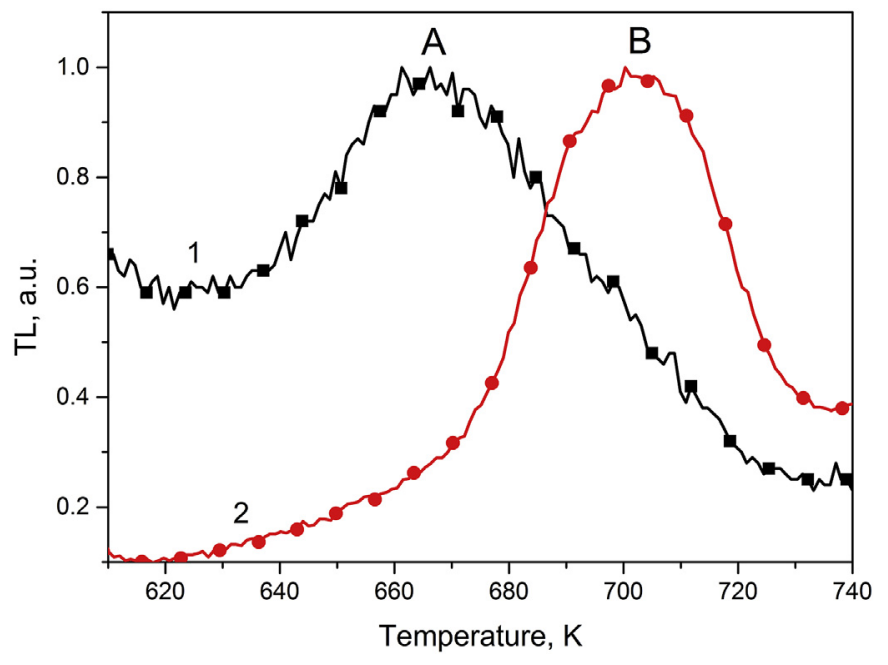

Fig. 3. Fragments of the normalized TSL curves from Fig. 2 typical of the bleaching of deep traps at $T=610-740 \mathrm{~K}$ in the samples of group A and B, respectively.

\section{Results and discussion}

Fig. 2 demonstrates two typical examples of TSL curves measured after high-dose irradiation ( $15 \mathrm{kGy}$ ) of the studied crystals by a pulsed electron beam. It can be seen that the TSL curves contain the main dosimetric peak at $400-500 \mathrm{~K}$ (labelled as MT) as well as several deeptrap-related peaks (DT1, DT2, DT3). The intensity of deep trap peaks varied significantly from sample to sample. The nature of deep traps in the crystals under study has not been reliably established. According to (Lapraz et al., 1991), the TSL peak at 500-600 K (DT1) is due to the recharging of chromium impurity ions. In addition, the TSL at $630-750 \mathrm{~K}$ has been previously attributed to electron traps, while the trap associated with the TSL at $800-870 \mathrm{~K}$ has a hole nature (Nikiforov et al., 2014; Yukihara et al., 2003).

In the present paper, new features of TSL build-up for the TSL peak at $630-750 \mathrm{~K}$ (DT2 traps) are revealed in anion-deficient aluminum oxide irradiated with a pulsed electron beam. Note that a complex structure of this peak has already been established earlier. This complicity can be illustrated in Fig. 3 using two normalized curves of TSL at $T=610-740 \mathrm{~K}$. The analysis of TSL shape in this temperature region allows to separate a so-called group A of samples with the dominant peak at $660 \mathrm{~K}$ (see Figs. 2 and 3, curve 1), while the dominant peak at $700 \mathrm{~K}$ (curve 2) has been typical for the samples from the second group B. In addition, a well-pronounced double-peak TSL has been detected in several samples as well. The intensity ratio for these two peaks strongly varies from sample to sample.

The isothermal decay of TSL in the temperature range of DT2 traps measured for the samples of the two groups is shown in Fig. 4. One can see that TSL build-up is less noticeable for the samples of group A, in comparison with the samples of group B. For the samples of group B a clear tendency can be observed: the amplitude and the build-up duration of TSL decrease with increasing $\mathrm{T}_{\text {is }}$ (see also (Nikiforov et al., 2017)). A slight increase in the amplitude of the build-up when $T_{\text {is }}$ changes from 673 to $683 \mathrm{~K}$ lies within the limits of measurement errors. A similar tendency can be noticed also for the group A, however the TSL build-up is remarkably weaker and completely disappears at higher temperatures.

In the framework of the model under discussion, the decrease in amplitude and duration of the TSL build-up with an increase of $\mathrm{T}_{\text {is }}$ can be explained by the fact that the higher $\mathrm{T}_{\text {is }}$ in the DT2 range, the larger number of charge carriers are released from the DT2 traps during the preliminary linear heating. Consequently, the population of the DT2 traps with electrons is reduced at $\mathrm{T}_{\mathrm{is}}$, and the number of electrons injected to the conduction band at this temperature is also smaller. Thus, the effect of TSL build-up is less pronounced at higher temperatures and it completely disappears at sufficiently high $\mathrm{T}_{\text {is }}$ (Nikiforov et al., 2017).

According to (Nikiforov et al., 2014), the TSL peak at $630-750 \mathrm{~K}$ is mainly connected with the depopulation of the DT2 electron traps. Nevertheless, a simultaneous emptying of some part of hole traps in the same temperature region is possible as well. The build-up of the TSL in the peak at $700 \mathrm{~K}$ detected in the present paper for the samples of group $\mathrm{B}$ allows us to suggest an electron nature of this peak. On the other hand, the $660 \mathrm{~K}$ peak typical of the samples of group A may be mainly connected with hole traps, and, in accordance with the model in Fig. 1, there is no luminescence build-up in this peak.

The isothermal decay was measured also for the TSL peak at $573 \mathrm{~K}$ (DT1) in anion-deficient aluminum oxide after electron or UV irradiation. One can see that the TSL build-up for the DT1 region is evident after UV irradiation (Fig. 5b), but it is barely noticeable after pulsed electron beam irradiation (Fig. 5a). Fig. 5b demonstrates also that the behaviour of TSL related to the DT1 traps is similar to that for the DT2 traps: the amplitude and rise time decrease with increasing value of $T_{i s}$. The absence of the correlation between the amplitude/duration of build-up, on the one hand, and the value of $\mathrm{T}_{\text {is }}$ in Fig. $5 \mathrm{a}$, on the other hand, is tentatively ascribed to measurement inaccuracy caused by temperature gradient between the sample and heating element, which becomes more important in the region of weak TSL build-up.

The obtained results can be explained by considering the fact that the TSL peak at $573 \mathrm{~K}$, known to be associated with the recharging of chromium ions in $\mathrm{Al}_{2} \mathrm{O}_{3}$ (Lapraz et al., 1991), may contain both electron and hole components. A similar assumption was made in (Lapraz et al., 1991) to explain the mechanism of luminescence for chromium ions in ruby. The authors assumed that the $\mathrm{Cr}^{3+}$ impurity luminescence can be realized through both the recombination of an electron with a $\mathrm{Cr}^{4+}$ ion and a hole with a $\mathrm{Cr}^{2+}$ ion. Thus, TSL in electron-irradiated samples can be caused by both electron and hole traps, which are filled by the radiation-induced electron-hole pairs at the interband transitions. In this case, the resulting isothermal curve is a superposition of the TSL build-up of electron traps and TSL decay of hole traps, so the effect of the TSL build-up is less pronounced.

On the other hand, it is known that UV irradiation fills only electron traps in $\mathrm{Al}_{2} \mathrm{O}_{3}$ due to the photoionization of $\mathrm{F}$ centres (Summers, 1984). The excitation of the $\mathrm{F}$ centre by UV light leads to the intracentre transition from the ground state ${ }^{1} \mathrm{~S}$ to the excited state ${ }^{1} \mathrm{P}$. Since the excited ${ }^{1} \mathrm{P}$ state of the $\mathrm{F}$ centre is located close to the bottom of the conduction band, its ionization occurs resulting in the formation of an $\mathrm{F}^{+}$centre and a conduction electron, which can be captured by the dosimetric (labelled as MT in Fig. 2) and other deep traps. The TSL related to electron traps in $\mathrm{Al}_{2} \mathrm{O}_{3}$ is known to occur due to the emission of $\mathrm{F}$ centres, according to the reaction:

$\mathrm{F}^{+}+\mathrm{e} \rightarrow \mathrm{F}^{*} \rightarrow \mathrm{F}+\mathrm{h} \nu(3 \mathrm{eV})$

One can expect that the TSL build-up will be pronounced more clearly after UV irradiation than after electron irradiation, since its occurrence is associated with electron trapping and recombination processes related to $\mathrm{F}$ centres. These arguments are in agreement with the experimental data presented in Fig. 5b.

Up to the present, we have studied only integral effect of the TSL build-up connected with deep traps in aluminum oxide. At the same time, in order to confirm the adequacy of the model considered in the present paper, it is interesting to study the build-up effect for separate spectral components of TSL. The emission spectra of TSL at the temperatures related to DT1 traps were measured in the UV-irradiated $\mathrm{Al}_{2} \mathrm{O}_{3}$ single. The typical emission spectrum (see Fig. 6) contains three bands peaked at $2.91,2.25$ and $1.78 \mathrm{eV}$. The emission at $2.91 \mathrm{eV}$ is dominant and well coincides with the luminescence band of $\mathrm{F}$ centres in $\mathrm{Al}_{2} \mathrm{O}_{3}$ (Evans et al., 1994). The luminescence band with a maximum at 

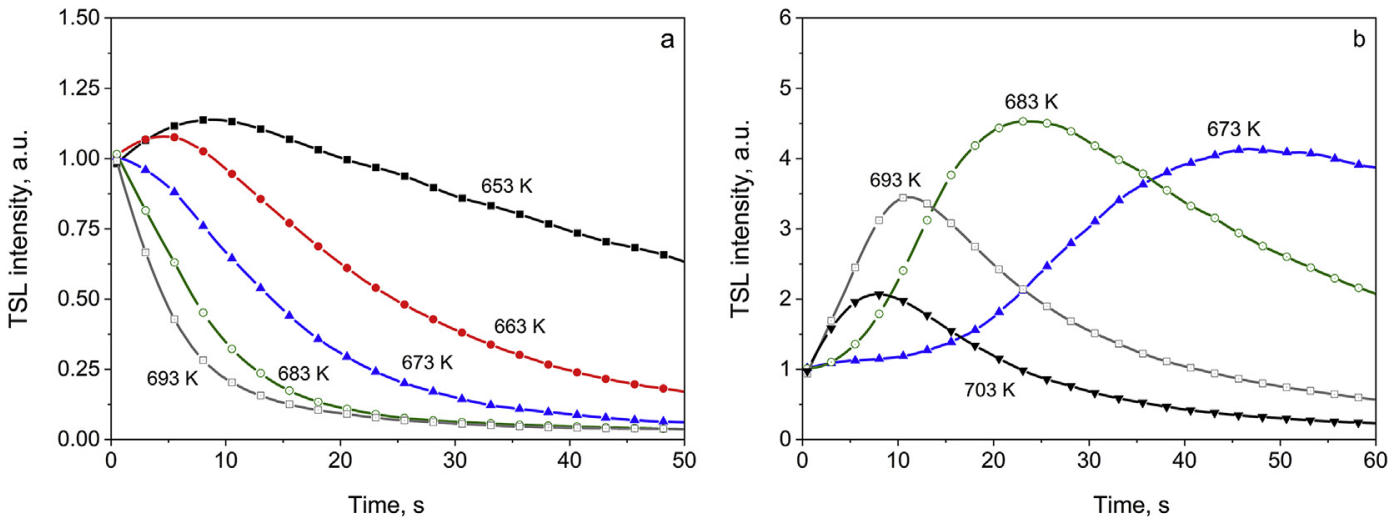

Fig. 4. Isothermal decay of $T S L$ at different temperatures $T_{i s}$ for the samples of group $A\left(T_{m}=660 \mathrm{~K}\right)$ (a) and $B\left(T_{m}=700 \mathrm{~K}\right)$ (b) after electron irradiation with the dose of $15 \mathrm{kGy}$. The heating rate was $2 \mathrm{~K} / \mathrm{s}$.
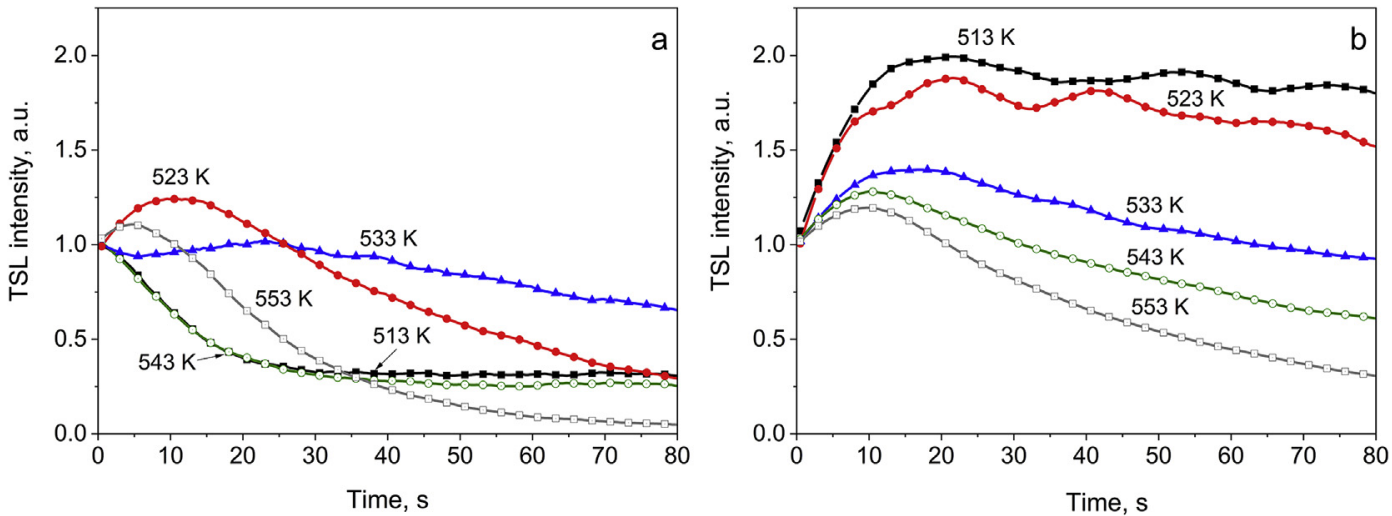

Fig. 5. Isothermal decay of the TSL related to DT1 traps at different temperatures $T_{i s}$ in the samples irradiated with a pulsed electron beam to the dose of $15 \mathrm{kGy}$ (a) and UV light (b). The heating rate was $2 \mathrm{~K} / \mathrm{s}$.

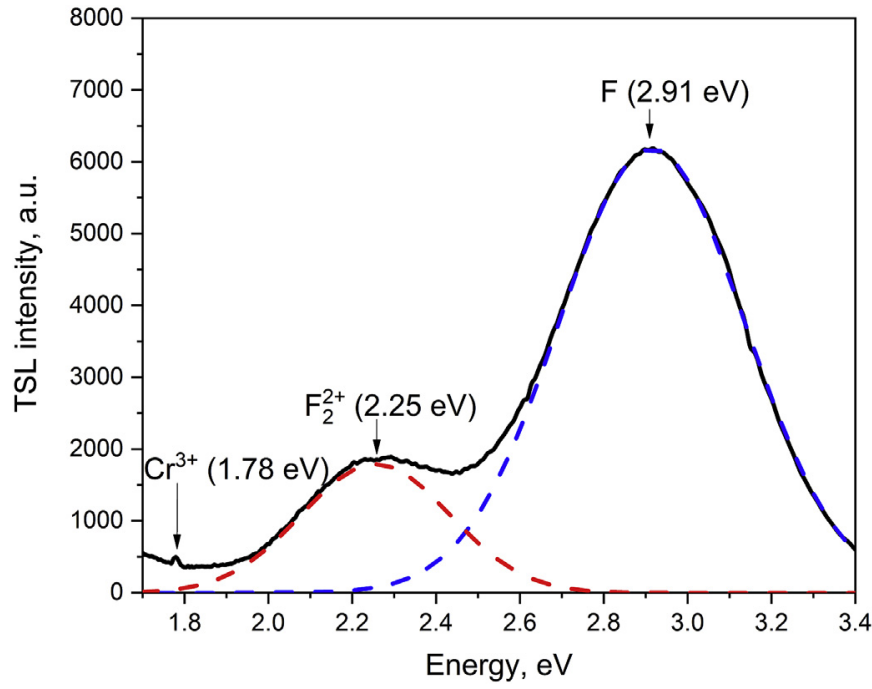

Fig. 6. Emission spectrum of the TSL at 560-580 K in an UV-irradiated sample.

$1.78 \mathrm{eV}$ is rather weak and consists of a narrow R-line of impurity $\mathrm{Cr}^{3+}$ ions (Singh et al., 2012). The luminescence at $2.25 \mathrm{eV}$ can be associated with the aggregate $\mathrm{F}_{2}{ }^{2+}$ centres (an oxygen divacancy with two captured electrons) (Izerrouken and Benyahia, 2010). Note that the emission of aggregated $\mathrm{F}_{2}{ }^{2+}$ centres was registered earlier in the emission spectrum of TSL connected with DT1 in X-ray irradiated $\mathrm{Al}_{2} \mathrm{O}_{3}$ single crystals (Kortov et al., 2017).

To verify the model of TSL build-up, which involves the process of

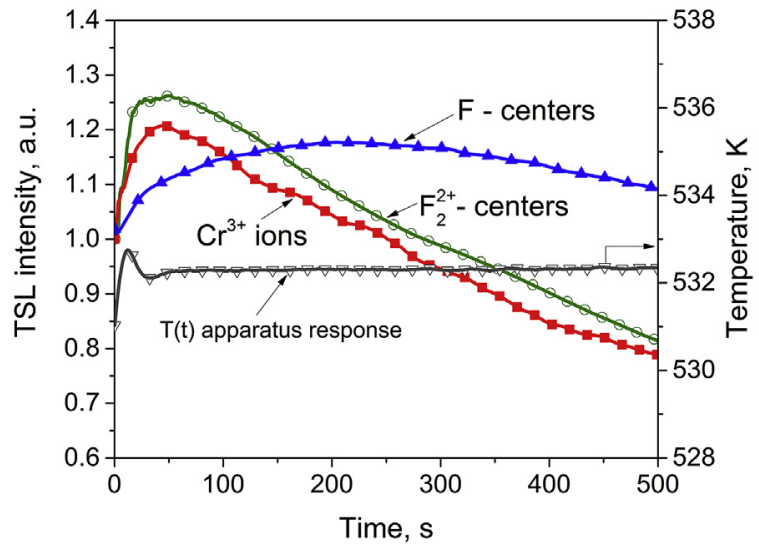

Fig. 7. Isothermal decay of the TSL at $532 \mathrm{~K}$ (DT1 traps) measured for the emission of $\mathrm{F}$ and $\mathrm{F}_{2}{ }^{2+}$ centres or $\mathrm{Cr}^{3+}$ ions in an UV-irradiated sample as well as temperature dependence of apparatus response for the setup used. The heating rate was $0.5 \mathrm{~K} / \mathrm{s}$.

the thermal ionization of F centres, the decay of TSL at the increasing part of DT1-related peak was measured for the emissions of $\mathrm{F}(2.91 \mathrm{eV})$ and $\mathrm{F}_{2}{ }^{2+}(2.25 \mathrm{eV})$ centres as well as $\mathrm{Cr}^{3+}$ ions $(1.78 \mathrm{eV})$. According to Fig. 7 , the TSL detected for the emission of $\mathrm{F}_{2}{ }^{2+}$ centres and $\mathrm{Cr}^{3+}$ impurity ions is characterized by the same decay kinetics. A slight initial increase of TSL intensity is associated with insignificant fluctuations during establishing a selected temperature $T_{\text {is }}$ for the isothermal measurement. To confirm this statement, the temperature dependence of apparatus response for the setup used is also presented in Fig. 7. At the same time, decay kinetics for the F-centre emission differs 
significantly from those for other emissions. There is a long build-up of $200 \mathrm{~s}$ for the F-centre emission (see Fig. 7), which can be considered as a direct proof of the involvement of thermal ionization of the F-centre excited states. Low intensity of the TSL build-up in the F-centre emission (Fig. 7) compared with the build-up of the integral TSL intensity (see Fig. 5b) is associated with a lower rate of the preliminary heating used at the measurement for the spectral components of TSL. A similar situation was discussed earlier in (Nikiforov et al., 2017). A decrease in heating rate leads to a shift of the TSL peak towards lower temperatures. This circumstance, in turn, causes a lower occupation of the traps by electrons at the beginning of the isothermal heating and, consequently, a lower electron concentration in the conduction band and a drop in the intensity of the TSL build-up.

\section{Conclusion}

1. New features of TSL related to deep traps in $\alpha-\mathrm{Al}_{2} \mathrm{O}_{3}$ single crystals irradiated by a pulsed electron beam are established. TSL of deep traps at $\mathrm{T}=630-750 \mathrm{~K}$ is characterized by a complex structure containing at least two elementary components at 660 and $700 \mathrm{~K}$. Isothermal build-up of TSL is observed only in the samples characterized by the presence of the high-temperature component with $\mathrm{T}_{\mathrm{m}}=700 \mathrm{~K}$.

2. The isothermal build-up of TSL at $573 \mathrm{~K}$ is well expressed in UVirradiated samples and is very weak after the sample irradiation by a pulsed electron beam. This difference can be explained by the fact that only electron traps are filled due to the ionization of the excited F centres in the samples exposed to UV radiation. On the other hand, in the case of electron irradiation, the hole centres are also populated alongside with electron ones by the radiation-induced electron-hole pairs. As a result, in contrast to the case of UV-irradiated samples, the hole processes mask up the TSL build-up.

3. The obtained results confirm the kinetic model of TSL build-up that takes into account the process of thermal ionization of the excited states of $\mathrm{F}$ centres in aluminum oxide. A noticeable build-up of TSL at $573 \mathrm{~K}$ measured for the F-centre emission as well as the absence of this effect for the luminescence of $\mathrm{F}_{2}{ }^{2+}$ centres and chromium ions is a direct verification of the proposed model.

\section{Acknowledgment}

This work was financially supported by the Russian Science Foundation, project No. 18-72-10082 and Estonian Research Council, projects IUT2-26 and PUT PRG111.

\section{References}

Afanasev, V.N., Bychkov, V.B., Lartsev, V.D., Pudov, V.P., Solomonov, V.I., Shunailov, S.A., Gromov, A.A., 2005. Parameters of the electron beams generated by the RADAN-220 and RADAN EXPERT accelerators. Instrum. Exp. Tech. 8, 641-645.

Akselrod, M.S., Kortov, V.S., Kravetsky, D.J., Gotlib, V.I., 1990. Highly sensitive thermoluminescent anion-defective $\alpha-\mathrm{Al}_{2} \mathrm{O}_{3}: \mathrm{C}$ single crystal detectors. Radiat. Protect. Dosim. 32, 15-20.

Bos, A.J.J., 2001. High sensitivity thermoluminescence dosimetry. Nucl. Instrum. Methods B 184, 3-28.

Chithambo, M.L., Seneza, C., Ogundare, F.O., 2014. Kinetic analysis of high temperature secondary thermoluminescence glow peaks in $\alpha-\mathrm{Al}_{2} \mathrm{O}_{3}$ :C. Radiat. Meas. 66, 21-30.

Evans, B.D., 1995. A review of the optical properties of anion lattice vacancies, and electrical conduction in $\alpha-\mathrm{Al}_{2} \mathrm{O}_{3}$ : their relation to radiation-induced electrical degradation. J. Nucl. Mater. 219, 202-223.

Evans, B.D., Pogatshnik, G.J., Chen, Y., 1994. Optical properties of lattice defects in $\alpha$ $\mathrm{Al}_{2} \mathrm{O}_{3}$. Nucl. Instrum. Methods B 91, 258-262.

French, R.H., Jones, D.J., Loughin, S., 1994. Interband electronic structure of $\alpha$-alumina up to 2167 K. J. Am. Ceram. Soc. 77, 412-422.

Itoh, N., Stoneham, A.M., 2000. Material Modification by Electronic Excitation. Univ. Press, Cambridge.

Izerrouken, M., Benyahia, T., 2010. Absorption and photoluminescence study of $\mathrm{Al}_{2} \mathrm{O}_{3}$ single crystal irradiated with fast neutrons. Nucl. Instrum. Methods B 268, 2987-2990.

Kirm, M., Zimmerer, G., Feldbach, E., Lushchik, A., Lushchik, Ch, Savikhin, F., 1999. Selftrapping and multiplication of electronic excitations in $\mathrm{Al}_{2} \mathrm{O}_{3}$ and $\mathrm{Al}_{2} \mathrm{O}_{3}: \mathrm{Sc}$ crystals. Phys. Rev. B 60, 502-510.

Kortov, V., Lushchik, A., Nagirnyi, V., Ananchenko, D., Romet, I., 2017. Spectrally resolved thermally stimulated luminescence of irradiated anion-defective alumina single crystals. J. Lumin. 186, 189-193.

Kotomin, E.A., Popov, A.I., Stashans, A., 1994. A novel model for $\mathrm{F}^{+}$to $\mathrm{F}$ photoconversion in corundum crystals. J. Phys. Condens. Matter 6, L569-L573.

Lapraz, D., Iacconi, P., Daviller, D., uilhot, B., 1991. Thermostimulated luminescence and fluorescence of $\alpha-\mathrm{Al}_{2} \mathrm{O}_{3}: \mathrm{Cr}^{3+}$ samples (ruby). Influence of the $\mathrm{Cr}^{3+}$ concentration. Phys. Status Solidi 126, 521-531.

Lushchik, A., Lushchik, Ch, Schwartz, K., Vasil'chenko, E., Kärner, T., Kudryavtseva, I., Isakhanyan, V., Shugai, A., 2008. Stabilization and annealing of interstitials formed by radiation in binary metal oxides and fluorides. Nucl. Instrum. Methods B 266, 2868-2871.

Makhov, V.N., Lushchik, A., Lushchik, ChB., Kirm, M., Vasil'chenko, E., Vielhauer, S., Harutunyan, V.V., Aleksanyan, E., 2008. Luminescence and radiation defects in electron-irradiated $\mathrm{Al}_{2} \mathrm{O}_{3}$ and $\mathrm{Al}_{2} \mathrm{O}_{3}$ :Cr. Nucl. Instrum. Methods B 266, 2949-2952.

McKeever, S.W.S., Akselrod, M.S., Colyott, L.E., Agersnap Larsen, N., Polf, J.C., Whitley, V.H., 1999. Characterisation of $\mathrm{Al}_{2} \mathrm{O}_{3}$ for use in thermally and optically stimulated luminescence dosimetry. Radiat. Protect. Dosim. 84, 163-168.

Milman, I.I., Kortov, V.S., Nikiforov, S.V., 1998. An interactive process in the mechanism of the thermally stimulated luminescence of anion-defective $\alpha-\mathrm{Al}_{2} \mathrm{O}_{3}$ crystals. Radiat. Meas. 29, 401-410.

Nikiforov, S.V., Kortov, V.S., 2010. Effect of deep traps on sensitivity of TLD-500 thermoluminescent detectors. Radiat. Meas. 45, 527-529.

Nikiforov, S.V., Kortov, V.S., 2014. Dosimetric response for crystalline and nanostructured aluminium oxide to a high-current pulse electron beam. Radiat. Protect. Dosim. 162 (1-2), 92-95.

Nikiforov, S.V., Kortov, V.S., 2017. The contribution of hole traps to thermoluminescence of the dosimetric peak in anion-defect $\alpha-\mathrm{Al}_{2} \mathrm{O}_{3}$ single crystals. Phys. Solid State 59, 1717-1724.

Nikiforov, S.V., Kortov, V.S., Zvonarev, S.V., Moiseykin, E.V., Kazantseva, M.G., 2014 Basic thermoluminescent and dosimetric properties of $\mathrm{Al}_{2} \mathrm{O}_{3}: \mathrm{C}$ irradiated by pulse intensive electron beam. Radiat. Meas. 71, 74-77.

Nikiforov, S.V., Kortov, V.S., Oduyeva, L.O., Merezhnikov, A.S., Ponomareva, A.I., Moiseykin, E.V., 2017. Isothermal build-up of deep trap thermoluminescence of anion-defective alumina crystals. Radiat. Meas. 106, 519-524.

Pagonis, V., Chen, R., Maddrey, J.W., Sapp, B., 2011. Simulations of time-resolved photoluminescence experiments in $\alpha-\mathrm{Al}_{2} \mathrm{O}_{3}$ :C. J. Lumin. 131, 1086-1094.

Popov, A.I., Lushchik, A., Shablonin, E., Vasil'chenko, E., Kotomin, E.A., Moskina, A.M., Kuzovkov, V.N., 2018. Comparison of the F-type center thermal annealing in heavyion and neutron irradiated $\mathrm{Al}_{2} \mathrm{O}_{3}$ single crystals. Nucl. Instrum. Methods B 433 93-97.

Singh, V., Chakradhar, R.P.S., Rao, J.L., Al-Shamery, K., Haase, M., Jho, Y.D., 2012. Electron paramagnetic resonance and photoluminescence properties of $\alpha-\mathrm{Al}_{2} \mathrm{O}_{3}: \mathrm{Cr}^{3+}$ phosphors. Appl. Phys. B 107, 489-495.

Summers, G.P., 1984. Thermoluminescence in single crystal alpha- $\mathrm{Al}_{2} \mathrm{O}_{3}$. Radiat. Protect. Dosim. 8, 69-80

Surdo, A.I., Milman, I.I., Abashev, R.M., Vlasov, M.I., 2014. High-temperature thermoluminescence of anion-deficient alumina and possibilities of its application in highdose dosimetry. Tech. Phys. Lett. 40, 1048-1051.

Surdo, A.I., Abashev, R.M., Milman, I.I., Moiseykin, E.V., 2016. Accumulation features and TL of TLD-500 detectors in a wide temperature range at pulsed and continuous high-dose irradiation. Radiat. Meas. 90, 192-195.

Valbis, J., Itoh, N., 1991. Electronic excitations, luminescence and lattice defect formation in $\alpha-\mathrm{Al}_{2} \mathrm{O}_{3}$ crystals. Radiat. Eff. Defect Solid 116, 171-189.

Yukihara, E.G., Whitley, V.H., Polf, J.C., Klein, D.M., McKeever, S.W.S., Akselrod, A.E. Akselrod, M.S., 2003. The effects of deep trap population on the thermoluminescence of $\mathrm{Al}_{2} \mathrm{O}_{3}:$ C. Radiat. Meas. 37, 627-638. 